\title{
XXIII. Solutions of Sir H. C. Englefield's mathematical question given in the last number of this journal
}

\section{George Harvey}

To cite this article: George Harvey (1814) XXIII. Solutions of Sir H. C. Englefield's mathematical question given in the last number of this journal , Philosophical Magazine Series 1, 43:190, 107-113, DOI: $10.1080 / 14786441408637982$

To link to this article: http://dx.doi.org/10.1080/14786441408637982

电 Published online: 27 Jul 2009.

Submit your article to this journal $₫$

Џll Article views: 3

Q View related articles $₫$ 


\section{[ 107 ]}

XXIII. Solutions of Sir H. C. ENGLefierd's Mathematical Question given in the last Number of this Journal.

SIRs,-I BFG leave to present you with the following solution to the question proposed by Sir H. C. Englefield, Bart. F.R.S. F.A.S. \&c. in the last number of your most excellent Ragarine; and at the same time take the liberty to rcmark, that in the stating of the question I think a small typographical error has crept; for the two last, read the two first (11 th line, page 64).

All numbers under a million must consist of six figures or less, and consequently the cube roots of all such numbers must contain two figures or less. In numbers whose roots have only one figure, no difficulty can be found, as their ronts can be obtained from sinple inspection: the remaining case is then that of such cubes that their roots may contain two digits. In orier to obtain the first digit, from the given number of figures subtract three, and of the remaining figures we by the supposition know the two frrst, and thus we obtain a number concisting of either one, two, or three digits: the nearest root of this number may be immediatcly found by simple inspection; and that root will be the first digit of the number reçuired.

The second digit of the root may be obtained by considering that all inmbers must end either in 0 , or in some of the nine digits: now the cubes of these digits are respectively $0,1,8,27$, $64,125,216,343,512$ and 729 ; therefore the culies of all numbers ending in $0,1,2,3,4,5,6,7,8$, or 9 , must terminate in 0 , $1,8,7,4, \tilde{5}, 6,3,2$, or 9 . From this consideration it is evident, that knowing the terminal digit of any cube, we can immediately by inspection determine that of the root, and thus the first digit being before found, we obtain the root itself.

Thus, in the example the learned Baronet has given : from the given number of figures (6) subtract three, and three will remain; we therefore, affix a cypher to the two given figures 43 , and obtain 430, whose nearest root is 7 . The terminal figure being 6 , we find that the last figure of the root must also be 6 ; and therefore the root required must be 76 , whose cube is 438996 . I take the liberty of proposing, for the amusement of your scientific readers, the two following questions: I thi:k they have buth been before proposed, but imagine that they admit of more interesting solutions than have hitherto appeared.

1. Required a method of, determining at sight, or by simple inspection, whether any given number be a prime number or not.

2. By what methods could the Romans solve simple arithmetical questions with their mode of notation?
I remain, gentlemen,
Your obedient humble servant,
To Messrs. Nicholson and Tilloch. Egertun S, Eyres. 
Chichester, Feh. 5, 1814.

SiR H. Fxglefreld's mathematical question published in your last number may, I believe, be solved in the following manner:

The cube root of every number under a million must of course consist of not more than two places of figures. Of these the last may be inmediately determined, by observing that with regard to six of the ten integers, viz. $1,4,5,6,9$, and 0 , the unit's place is always the same in the cube and its root; while 2 and 8,3 and 7 , are reciprocally changed one into the other in the processes of involution or evolution.

The other figure of the root may be obtained as in the common rule for extracting the third power, viz. by dedueting 3 from the given number of places, and taking the root of the cube next less than the amount indicated by the one, two, or three figures remaining on the left hand.

Thus, in the example proposed, where we have given the unit's place 6 , the two first figures 43 , the number of places 6 ;

The unit's place in the root will of course be 6 , as in the cube.

Deducting 3 from the number of places, there remain 3; therefore, alfixing a cypher to the two first figures, we obtain 430 . The cube next less than this is 343 , of which the root is 7 . The root required is therefore 76 .

In this way, I find I can obtain the root of any cubic number almost instantaneously; but I can hardly suppose so simple and obvious a principle to have escaped the notice of mathematicians,

Srns,-Having bcen induced by the letter of Sir H. C. Englefield, inserted in your last, to turn my attention to the subject of his inquiry; I am enibled by the following simple process to name immediutely the root of any eube under a million, whose two first figures, last figure, and number of figures are given.

All that appears necessary for the performance of this problem is a knowledge of the eubes of the digits. As the root consists of two figures, its tens will be indicated by, and must be sought for in, its two first figures, and its units in the last figure given.

By observing the number of fiyures in the cube we previously discover the value of the two first figures given, whether they contain the units only, or the tens and units, or the hundreds and tens of the first figure of the root when cubed: having ascertained this, we compare these figures with the cubes of the digits, and call that digit with whose cube they correspond, or to which they are next in superiority, the first figure of the root.

The last figure given, which is of course the unit of the cube, will produce the second figure, or unit of the root, by this simple rule: 
rule : $1,4,5,6,9,0$, remain unaltered, while 3 and 7,2 and 8 , are respectively convertible into each other; or each when occurring in the cube may be represented in the root by what it wants of 10 .

The instance adduced by Sir H. C. Englefield is a cube of 6 figures, the two first of which are 43 , and the last is 6 . Now as in a cube of 6 figures, the cubed tens of the root exist in the three first figures, these twn first, here given, must contain the laundreds and tens of that cube, and 43 represent 430 (the amount of the unit's place being immaterial). The regular cube next below 430 is 343 , whose root $(7)$ is consequently the first figure required. For the second figure, 6 in the cube gives, as before explained, 6 in the root, and the whole root is therefore 76 .

I know not if this be the method used by Sir H. C. Englefield, and shall be happy to see any others suggested by your correspondents ; but must observe that this appears amply sufficient for the purpose, as by it any one, after a practice of less than half an hour, may tell the root of any number, within the bounds of the question, as soon as proposed to them.

$$
\begin{aligned}
& \text { I remain, sirs, } \\
& \text { Your very obedient servant, }
\end{aligned}
$$

\section{To Messrs. Nicholson and Tilloch.}

John DrLlon.

\section{Lansdum Crescent, Bath, Feb. 10, 1814.}

SrRs,-The solution of the following question proposed in your last Magazine is not difficult.

"Of any cube number under a million, give the figure of the unit, the two first figures, and the number of places, instantly and without any ail of writing to name its cube root."

In every cube number, two figures, the first and last, may be known by simple inspection; the first being the nearest cube root under the first or left hand period, whether consisting of one, two, or three figures, and the last being invariably indicated by the final digit. Thus, if the final digit be 2 , the last figure of the root will be 8 ; if it be 3 , the root indicated will be $7:$ a table of the cubes of all the single digits at once exhibits the unvarying correspondence between the final digit of the cube and its root. Now, according to the conditions of the question, the cube whose root is sought, can never exceed six places of figures: consequently the root must consist merely of a first and a last figure, which we have seen may be instantly discovered by simple inspection. It is true, the intermediate figures between the final digit and the two first figures are not given; but the number of places being given, it is (for an obvious reason) only necessary 


\section{Solutions of Sir H.C. Englefield's Mathematical Question.}

mentally to substitute noughts in the places of the unknown intermediate figures.

I shall smijoin three examples, which comprehend all the varieties of the question; and am, sirs, your obedient servant, Francis Ellis.

Given $94 . .2$. Here the number of places being six, the first period (according to the rule for extracting the cube root) must consist of thre a figures, which after the mental substitution of noughts will be 940 , whose nearest less cube root is 9 , and the final digit 2 , indicating $S$ for the remaining figure of the root: the entire root is "insianly and willout any aid of writing" perceived to be 98 .

Given 50 . 3. The number of places being five, the first period must consist of only two figures, which are $(59)$, the two furst given, whose nearest less cube root is 3 , and the final digit 3 , indicating 7 for the other figure of the root: the whole root is 37 .

Given $6,8.9$. The number of places being only four, the first period consists of the single figure 6 , whose nearest less cube root is 1 , and the final digit 9 , indicating 9 for the other figure of the root: the whole root is at once found to be 19 .

The number 438976 , given by Sir H.C. Englefeld, is not a cuhe number*

To Messrs. Nicholson and Tilloch.

Royal Military Academy, Woolwich, Feb. 12, 1814.

SIRs,-CIT gave ine great pleasure to observe the sentiments with which Sir II. C. Englefeld introduced his question in your last number, relative to the extraction of certain cube roots. He there justly states, thiat it is not common to introdnce questions of this kind to the public through the medium of periodical Joumids, though it was not unusual in the early part of the last century; and every one acruainted with the progress of the sciesces at that jeriod will admit that much of it was to be atiributed to such communications. I made a similar remark sune little time back, in proposing a question in the Philosophical Joumal, under the signature of " Mathematicus;" and though I failed in my attempt to bring the subject under examination at that time, I am not without hopes that the example of a geritleman, so well known and csteened in the scientitic world as Sir H. F. is, may be followed by other:, and that we may thus see, at times, a few pages of your valuable Magazine employed on subjects of this nature.

With respect to the question proposed, it is far from difficult, nothing further being necessary for its solution, than that of re-

* Probably a typoyraphical crror. Read 138996.-EDrx. 
membering the cubes of the nine digits. For all numbers ending in the same digit, having their cubes ending also in a constant digit, it follows that the terminating figmre of the cube will inmediately indicate the unit's place of the root; that is, If the terminating figure of the cube be $1,2,3,4,5,6,7,8,9$, that of the root is $\quad \ldots \quad \ldots \quad 1,8,7,4,5,6,3,2,9$. And with regara to the other figure of the root, or that in the tens place, it is found with equal ease from the leading figures of the cube, viz. If the three r"ght-hand figures be supposed to be pointed off, the nearest cube root to the remaining figures will be the figure in the tens place of the root: or, which is the same, If after pointing off the three right-hand figures, those remaining exceed $1,8,27,64,125,216$, \&e. the figure in the tens place will be accordingly $1,2,3,4,5,6,8 c$. and which, therefore, is known as readily from the three leading figures of the cube (or from the two leading ones, if the number of them be also known) as that of the unit's place is by the termination of the culse.

Suppose, for example, the cube root of 655503 were required.

The nearest integral cube root of 658 is 8 , and the terminating figure being 3 , that of the root is 7 ; therefore the root is 87 . And it wonld have been just the same if we had only known the two first figures 6.3 , provided we had at the same time known that there were three figures in the period, or, which is the same, six figures in the proposed cube; and in the same manner may the cube root of any other cube number, within the proposed limits, be immediately ascertained.

It is undoubtedly on these principles that $Z$. Colbourn performs his extractions of the cube root, and which he can apply with great ease to 12 figures, or to four, in the root. But in order to effect this, it is necessary for him to know the two terminating figures of the first 100 numbers, which he is perfectly master of; but whether absolutely from memory, or from it very rapid roultiplication it is difficult to say. At all events, he is able to name them with great rapidity; and I have by me a table of this kind, which was set down from his dictation, and is correct in every figure.

He undoubtedly owes much to an extraordinary memory, as well as to a remarkably ready perception of the qualities and properties of numbers; of which I could mention many instances, relating to the summation of arithmetical and geometrical progressions, the naming of prime numbers, \&c. In one instance, he repeated to me every prime number in its order from 1 to 600 , with only one mistake, which he corrected immediately, and was very anxious to be allowed to proceed to 1000 . But here it was obvious that he did not depend upon his memory only, but on a sort of computation. I know ic las been stated thet what he can perform 


\section{Solutions of Sir H. C. Englefield's Mathematical Question.}

perform in arithmetical computations is the result of tuition; and that he will not discover his methods. This however, so far as my observations have been extended; in several examinations of him both in company and in private, I can positively contradict. All his ideas were obviously intuitive, yet in most cases correct : indeed the only instance in which I found that he proceeded on false principles was in resolving numbers into their factors; and even here he would sncceed in the greater number of cases.

These examinations were undertaken for the purpose of giving a sketch of his methods or rules (if they may be so called); in a work which his father intended, and 1 believe still intends; to publish by subscription, containing an account of this remarkable boy; and I therefore do not wish to enter into further particulars in this place, lest his father should imagine it to be injurious to the interests of that publication. But if that plan should be ultimately given up, I may at some future time furnish you with what I have been able to ascertain on this subject; not that I conceive any one of his methods can be employed to any useful purpose; they are peculiarly his own, and can only be advantageously employed by hiniself; but as a subject of curiosity they may be acceptable to some of your readers.

To Messrs. Nicholson and Tilloch. I am, sirs; yours, sic.

\section{Peter Barlow.}

Plvmont $\},$ Teb. 8, 1814.

SiRs,-Fveny atiempt to simplify and abridge calculation deserves attention, and I cannot therefore but view the question proposed by Sir H. Fnglefield, in your number for Jenuary; with particular pleasure and satisfaction.

In order to resolve it, I would first remark, that when the unit's place in any root is .......... $0,1,2,3,4,5,6,7,8,9$, the unit's place in the cuhe will be $0,1,8,7,4,5,6,3,2,9$.

This table, of course, can be acquired in a few minutes by memory. To exenplify its use, we may briety state, that when the unit's place in any cube is 8 , the unit's place in the root will be 2 ; or when the unit's figure in the cube is 3 , the unit's place in the root will be 7 .

Moreover it is a well known law existing amongst cube numbers, that if any cube number be divided into periods of three figures commencing with the unit, the number of these periods will show the number of figures in the root, which in the case before us never can exceed two; that is, the root of every cube number under a million consists but of two figures, the first of which, or that in the unit's place, being readly obtained by the application of the above table, there remains only to discover the other figure, which is the cule rout of the greatest cube numler contained in the first period. 
An example or two will make this clear. Let the cube number whose root is required be 804357 . Here the first figure of the root will be 3 , and the root of the greatest cule contained in 804 is 9 . Hence the root recuired is $9:$.

Again. Required the asbe root of 74088. Here 2 is the first figure of the root, and the root of the greatest cube contained in 74 is 4 ; hence 42 is the root required.

If only the figure of the unit, the two frot figures, and the number of places be given, as tated in the queution, the operation will be precicly the same. For by taking the example given in the question, the fin st higne of the root in 6 ; and as the number consists of 6 pluces, it rematins oniv to fild the root of the greatest cubs mubs contained in 430 , which is 7 . Hence the root is 76 . It may be proper however to renark, thet this mode of stating the quection falls when the given cube number terminates witin a cypher.

Conceruing the performing this "instantly and without any aid of witing," I ber to observe, that when I first discovered the principle, I explained it to two or three young gentlemen, pupils of mine, aisont twelve years of age, and who,atter practining it for the short time of half an hour on a slate, wonld tell without the air of writing, the root of any cube number under a nidion, instantly, and without the smallest henitation.

The methor applies also te any cube minther above a million, when it terminates in a cyphar but I have not been alle to extend it to culve numbers in general. I make no donbt but that with a litule pains many other aritnotical operations night be simplified; and it would perhaps explatin in a way not the most unxatisfnetory, the truly astonshing powers of the "wonderful Anerican boy." I am, \&ce.

To Messrs. Nicholsm and Tilloch.

George Harvey.

XXIV. Ol'scrutions on the locctrines of definite Propertions in Chemical Ifinity Iy Wildiam CRane, Jun. M.D. of Bostum, Lincolnstire*.

$\mathrm{I}_{\mathrm{T}}$ $I_{\mathrm{T}}$ is ofren a pleasing tast: to view the progressive improvement that is atlentint upon diferent slepartments of science; in doing which we simctines meet with hypotheses that were comidered at firse as crude, riticulous, and soon alnovi iorgotien, ryatis revivest, more dearly illustrated, and not untresuenty advainced as enirely new. Ainon; many others that have been proponed in the science of chemi itry, that of hodies uniting in definite proportions to form chemical componnds holds a ristinguished place.

* Cormunicated by the anthor.

Vol. 43. No. 190. Fel. 1814.

Mr. 